\title{
Las herramientas se definen por su uso: Perspectivas en torno a la conceptualización de la dignidad humana
}

Tools are defined by their use: Perspectives on the conceptualization of buman dignity

As ferramentas são definidas pelo seu uso: Perspectivas sobre a conceituação da dignidade bumana

Les outils sont définis par leur utilisation: Perspectives sur la conceptualisation de la dignité bumaine

工具的用途定义如下: 关于人的尊严概念的观点

Giuliana Denisse Riera ${ }^{1}$ y María Gabriela Mateo $^{2}$

Universidad Nacional de La Plata - Argentina

Revista Derechos en Acción ISSN 2525-1678/ e-ISSN 2525-1686

Año 5/Nº 17 Primavera 2020 (21 septiembre a 20 diciembre), 224-236

DOl: https://doi.org/ https://doi.org/10.24215/25251678e458

Recibido: 01/09/2020

Aprobado: 15/09/2020

Resumen: El trabajo describe las tensiones en torno a la definición del concepto de dignidad humana, entendiéndolo como una herramienta

\footnotetext{
1 Abogada (FCJYS - UNLP), Maestranda en Derechos Humanos (FCJYS - UNLP), Estudiante de la Especialización en Derecho Penal (Facultad de Derecho - UBA). Dirección Postal: Diagonal 78 N 122, La Plata, Buenos Aires, Argentina, CP1900. Correo electrónico: giuliana. riera@pjba.gov.ar (ORCID: https://orcid.org/0000-0001-5819-4184)

2 Abogada (FCJYS - UNLP), Maestranda en Derechos Humanos (FCJYS - UNLP), Estudiante de la Especialización en Derecho Penal (Facultad de Derecho - UBA). Dirección Postal: calle 132 Nº 1867, La Plata, Buenos Aires, Argentina, CP1900. Correo electrónico: maria.mateo@ pjba.gov.ar (ORCID: https://orcid.org/0000-0002-3073-0632).
} 
hermenéutica sin contenido concreto que sirve a los operadores jurídicos para interpretar los Derechos Humanos y reconociéndolo como el fundamento último de la constitución de los derechos fundamentales de todos los seres humanos. Se lo aborda desde un punto de vista ético refiriendo a breves consideraciones de Imannuel Kant y Jürgen Habermas, en relación al concepto y desde un punto de vista semántico y jurídico en el análisis de las interpretaciones que de éste realizan los órganos de protección de Derechos Humanos.

Palabras clave: dignidad humana, Immanuel Kant, Jürgen Habermas, Derechos Humanos.

Abstract: The paper describes the tensions around the definition of the concept of human dignity, understanding it as an hermeneutic tool without a concrete content, that helps the legal operators interpretate human rights and acknowledging it as the ultimate basis of fundamental rights of every human being. It is approached from an ethic point of view, refering to brief considerations from Imannuel Kant and Jürgen Haberman in relationship to the concept, and from a semantic and a legal point of view in the analisis of the interpretations of the Human Right's legal bodies.

Keywords: human dignity, Immanuel Kant, Jürgen Habermas, Human Rights.

Resumo: Leste trabalho descreve as tensões em torno da definição do conceito de dignidade humana, entendendo-o como uma ferramenta hermenêutica sem conteúdo concreto que serve aos operadores jurídicos para interpretar os Direitos Humanos e reconhecendo-o como o fundamento último da constituição dos direitos fundamentais para todos. os seres humanos. É abordado do ponto de vista ético referindo-se a breves considerações de Imannuel Kant e Jürgen Habermas, em relação ao conceito e do ponto de vista semântico e jurídico na análise das interpretações feitas pelos órgãos de proteção dos direitos humanos. .

Palavras-chave: Dignidade humana, Immanuel Kant, Jürgen Habermas, Direitos Humanos

Résumé: Cette enquête décrit les tensions autour de la définition du concept de dignité humaine, le comprenant comme un outil herméneutique sans contenu concret qui sert les opérateurs juridiques à interpréter les 
Droits de l'Homme et le reconnaissant comme le fondement ultime de la constitution des droits fondamentaux pour tous les êtres humains. Elle est abordée d'un point de vue éthique en se référant à de brèves réflexions d'Imannuel Kant et Jürgen Habermas, en relation avec le concept et d'un point de vue sémantique et juridique dans l'analyse des interprétations qui en sont faites par les organes de protection des droits de l'homme

Mot-clés: dignité humaine, Immanuel Kant, Jürgen Habermas, Droits de I'homme

摘要：该作品描述了围绕人的尊严的定义的紧张关系，将其理解为 一种没有具体内容的解释工具, 为法律经营者提供了解释人权的途 径, 将其视为所有人的基本权利构成的最终基础人类. 它是从伦理学 角度出发的，是指伊曼纽尔·康德和尤尔根·哈贝马斯就该概念所作 的简短考虑, 并从语义和法律的角度分析了人权保护机构对其所作 的解释

关键字: 人的尊严, 伊曼纽尔·康德 (Kant), 于尔根. 哈贝马斯 (Habermas), 人权

\section{Introducción}

En el presente trabajo se abordarán distintas perspectivas descriptas en torno a la conceptualización de la dignidad humana y su impacto en el desarrollo del Derecho Internacional de los Derechos Humanos. Se pretende mostrar que el concepto de dignidad humana se configura como una categoría vacía, pues no es posible cristalizar su contenido, ni estandarizar su definición. Se trata de una "herramienta" interpretativa, fundamento de los derechos humanos, de altísima carga emotiva pero, en definitiva de contenido volátil capaz de mutar conforme a su intérprete en cada caso concreto. Es por ello que se trabajará desde el concepto en distintas dimensiones: la primera será la dimensión ética, por tanto recogeremos la noción encumbrada por Immanuel Kant para desarrollar luego la propuesta del filósofo y sociólogo alemán Jürgen Habermas, avanzando sobre 
la conceptualización de la dignidad humana como fuente de los derechos fundamentales en la experiencia concreta de las históricas violaciones a ella y como fundamento del principio de indivisibilidad de los derechos humanos. La segunda dimensión que trabajaremos será sobre la idea de la dignidad humana como categoría vacía -o por lo menos de contenido inestabley se presentará la idea de la definición por el uso -en clara alusión a los juegos del lenguaje de Ludwig Wittgenstein- pues entendemos que las palabras no son "etiquetas" de los objetos y que determinados conceptos se definen en su uso. Es por ello que podemos interpretar la dignidad humana conforme la función que esté cumpliendo en el campo. Así analizaremos sus funciones discursivas en casos concretos, puntualizando en algunos extractos de decisiones adoptadas por órganos de protección de Derechos Humanos.

El objetivo perseguido es la capitalización del inmenso desarrollo de un concepto dinámico que sirve a los operadores jurídicos a aplicar interpretaciones extensivas acorde a principios que tiendan a optimizar la protección del ser humano y entenderlo como una plataforma riquísima de creación y de conquista social.

\section{La dimensión kantiana}

La Filosofía kantiana tiene como premisa la idea del hombre como un fin en sí mismo, autónomo y merecedor de un respeto incondicionado y este valor proviene de la dignidad que le es inherente. La dignidad se concibe como un valor intrínseco de la persona moral sin equivalentes, diferenciándolo del precio asignado a las cosas. Para Kant, la dignidad es un atributo del ser humano por su pertenencia a una comunidad de seres morales y es aquello que lo "ennoblece ante todas las demás criaturas". ${ }^{3}$

3 Ob. Cit. en Michelini, Dorando J. (2010), pág. 43. 
Según la tesis de Aguirre-Pabón ${ }^{4}$ (2011) a la que adherimos, la noción kantiana de dignidad humana es un concepto político legal que se basa en el significado común de ese momento histórico, que refiere a la idea de ostentación de título legal de honor o desarrollo de un oficio o profesión determinado. Este sentido, es extendido por analogía a la filosofía moral en tanto valor único asignado a los seres racionales capaces de establecer y seguir leyes morales.

Aguirre-Pabón entiende que esta noción de dignidad se presenta como un valor interno absoluto por el cual las personas pueden demandar respeto de todos los seres racionales. Esta dignidad le da un título para medirse a sí mismo con los demás seres y valorarse en un pie de igualdad, pero el objeto de respeto no es la individualidad sino la pertenencia al rango de seres racionales. Asimismo, de esta tesis se desprende que es evidente que el desarrollo del pensamiento kantiano en materia de dignidad humana es fundacional de principios jurídico-políticos de los Derechos Humanos. Sin embargo, de una exégesis de la obra de Kant surge que resulta anacrónico entender el concepto actual de dignidad humana en relación con el encumbrado por Kant. Pues "dignidad" como sinónimo de "rango" resulta un término más político que propio de la filosofía moral; pero aún con ello podríamos tender lazos entendiendo que el concepto actual de dignidad humana también refiere a la idea de igualación hacia arriba del rango, por la que todo ser humano, sin distinción alguna es titular de la misma dignidad.

\section{La dimensión post-kantiana: Jürgen Habermas}

En The Concept of Human Dignity and the Realistic Utopia of Human Rights (2010) ${ }^{5}$, Habermas pretende demostrar que

\footnotetext{
4 Aguirre-Pabón, J,0 (2011) Dignidad, derechos humanos y la filosofía práctica de Kant. Vniversitas (online). N.123. pp. 45-74

5 Habermas, J. (2010) El concepto de dignidad humana y la utopía realista de los derechos humanos. Diánoia (online), vol.55, n.64.
} 
existe desde siempre una conexión entre la noción moral de dignidad humana y la constitución de los derechos humanos. Si bien, señala que la misma se ha evidenciado solo en el pasado reciente, sostiene que el concepto de dignidad humana no es una categoría vacía, sino que es fuente de los derechos fundamentales en la experiencia concreta de la violación de ésta. Además, resulta el fundamento del principio de indivisibilidad de los derechos humanos.

Reconoce la existencia del concepto de dignidad humana desde la antigüedad, su desarrollo filosófico actual sostenido a partir de las premisas Kantianas y su materialización jurídica sólo después de la Segunda Guerra Mundial. Habermas plantea a partir de esta realidad histórica, que el concepto de dignidad humana desempeña una función creativa, pues es partir de la experiencia del horror que pueden construirse nuevos derechos y revisarse los existentes. Entiende que primero la humillación labra la conciencia de los maltratados y luego se estructura jurídicamente.

Demuestra que el concepto de dignidad humana es aglutinante, en tanto es el fundamento de la indivisibilidad de los derechos humanos. Desde este punto de vista, ésta no puede verse realizada si no se hallan cubiertos derechos civiles, políticos, sociales, culturales y económicos en pie de igualdad.

Por otro lado, reconoce en la dignidad humana la función de "sismógrafo", en tanto registra lo constitutivo de un orden social democrático, por lo que los derechos fundamentales deben reconocerse en el marco de una asociación entre personas libres e iguales que han de respetarse entre sí.

Entiende a la dignidad humana como el portal a través del cual el sustrato igualitario y universalista de la moral se traslada al ámbito del derecho; y para demostrar esta función de "puente" entre el cambio de perspectiva que ocurrió con el traspaso de los "deberes morales" a "obligaciones legales", hace un racconto histórico que da cuenta de la secularización de los preceptos morales judeocristianos. Los que, al momento 
de ocurrir la racionalización del derecho, sobrevolaron en calidad de principios al derecho positivo.

En ese racconto reconoce una paradoja: la noción de "dignidad humana" no estaba originariamente orientada a la generalización o universalidad de derechos, sino que respondía a indicadores diferenciadores de estatus.

El autor define a los derechos humanos como una "utopía realista”, en la medida en que no proponen más imágenes engañosas de una utopía social que promete la felicidad colectiva, sino que fundan el ideal de una sociedad justa en las instituciones de los estados constitucionales

La conclusión a la que arriba Habermas en su texto es que el contenido moral de los derechos humanos es una conquista de las revoluciones del siglo XVIII. Pretender neutralizar esa tensión entre moral y derecho, y reducir el planteo de la condición meramente retórica de la dignidad humana vacía de contenido, deja a los derechos humanos expuestos a la peligrosa situación de erosión.

\section{La dignidad humana como herramienta argumentativa}

La constitución de los Derechos Humanos, aun cuando puede rastrear su origen en las primeras revoluciones burguesas o mucho antes, encuentra su concepción actual recién en el siglo XX con posterioridad a la Segunda Guerra Mundial; momento en el que comienza a introducirse el concepto de dignidad humana en los instrumentos jurídicos internacionales.

Sin embargo, Jürgen Habermas sostiene que la relación moral entre derechos humanos y dignidad humana existe desde siempre: la experiencia del horror, la indignación contra prácticas de degradación de la condición humana retroalimenta la apelación a los derechos humanos.

Así como desde una perspectiva ética la dignidad es aquello que diferencia a los hombres de las cosas, desde la lingüística Eugenio Coseriu considera que el lenguaje es quizás la forma 
más universal de cultura y la primera que distingue inmediata y netamente al hombre de los demás seres de la naturaleza. ${ }^{6}$

Si consideramos al lenguaje inscripto en una realidad social que a su vez construye y determina, podríamos decir que la creación del concepto de "dignidad humana" surge en relación a la experiencia de la deshumanización de actos degradantes de la condición humana, que necesitaron de la construcción de una idea que remita a aquello que a contrario sensu no deshumanice, no convierta al hombre en cosa.

Considerando que en cada lenguaje se halla contenida una concepción particular del mundo, podríamos pensar que la constitución del concepto de dignidad humana tal como se introdujo en los instrumentos internacionales de derechos humanos, remite a una concepción occidental de lo que se considera "humano" y "digno".

La dignidad humana en este sentido, se llena de contenido con los derechos reconocidos en Pactos Internacionales que dan cuenta de un catálogo de prerrogativas de los seres humanos por su condición de tales. Y es un concepto que sirvió -en términos prácticos- al no tener un contenido estático, al consenso para la firma y ratificación de estos tratados internacionales.

Ahora bien, desde un punto de vista de la Teoría de la Argumentación Jurídica, entendemos que existen tres momentos de interpretación: uno pre-legislativo, en el que se barajó la noción de la "dignidad humana" como una herramienta de consenso. Uno netamente legislativo en el que se pretendió dar tecnicismo jurídico vinculando el concepto a derechos determinados y con contenido definido. Y uno de aplicación jurídica, en la que el operador que interpreta debe aplicarlo para resolver un caso concreto. Podemos distinguir en estos tres momentos una instancia ética, una política y una jurídica-argumental,

6 Coseriu, Eugenio; La creación metafórica del lenguaje. Departamento de lingüística de la Universidad de la República, Montevideo, año 1956. Disponible en http://www.romling. uni-tuebingen.de/coseriu/publi/coseriu18.pdf 
respectivamente. $\mathrm{Y}$ es en esta última en la que el concepto adquiere mayor relevancia práctica.

En casos en los que el operador jurídico no halle respuesta en el silogismo judicial tradicional, de subsunción de la premisa fáctica a la premisa jurídica, utilizará lo que consideramos una herramienta hermenéutica preciosa: la dignidad humana. Para argumentar en el caso concreto, le otorga una posibilidad creativa, que de utilizarse debidamente sería el resquicio jurídico para alentar la condición de progresividad de los Derechos Humanos y el desarrollo de la protección del plan de vida de cada ser humano del mundo.

\section{Funciones de la dignidad humana}

El lingüista Roman Jackobson reconoce que existen en el lenguaje por lo menos cinco funciones que remiten a cada elemento del acto comunicativo: la informativa, en la que el lenguaje se utiliza para describir un estado de cosas; la directiva cuando se utiliza para dirigir las acciones del interlocutor; la emotiva, cuando se pretende expresar una emoción; a las que se le agregan la fática -se utiliza para verificar que el canal comunicativo se halle abierto- y la metalingüística, cuando el lenguaje se utiliza para referirse a sí mismo. De ello podemos observar que los conceptos además de tener una definición, deben analizarse en contexto para poder evaluar cómo se está utilizando el lenguaje y qué intencionalidad tiene el emisor al momento de dirigir un mensaje.

El concepto de dignidad humana aun cuando no puede reconocerse su contenido técnico en forma acabada, puede ser evaluado conforme la función con la que se inserta en el discurso. Así en su dimensión ética encontramos su función directiva, en su dimensión política la emotiva y en ocasiones estas funciones solapadas bajo la apariencia de referirse a una descripción del concepto cuando en realidad su uso es otro.

Asimismo dentro de la dimensión ética, Habermas reconoce como función de la dignidad humana la de "sismógrafo" de la 
realidad, como mencionamos en el apartado 3; la de puente entre la obligación moral y la obligación legal; a la que agregamos una tercera función creativa.

Los jueces son los encargados de "crear" en cada caso concreto e interpretar extensivamente el concepto de dignidad humana, a efectos de elevar el rango de protección de derechos de forma integral. Y esta función creativa es la que alimenta el concepto de la dignidad humana y coadyuva al desarrollo progresivo de los derechos humanos. Es la ductilidad del concepto lo que debe deslumbrarnos y no sucumbir al temor conservador positivista.

\section{La dignidad humana en los órganos de protección de Derechos Humanos}

A efectos de ilustrar la función creativa de los operadores jurídicos de protección de Derechos Humanos en casos concretos en relación a la dignidad humana, vamos a referirnos a un trabajo del año 2009 de Viviana Bohorquez Monsalve y Javier Aguirre Román en el que analizan cinco casos presentados ante la Corte Interamericana de Derechos Humanos en las que los jueces debieron determinar el alcance dado al concepto de dignidad humana. En honor a la brevedad abordaremos solo dos de ellos.

El primer caso trabajado es Velásquez Rodríguez vs Honduras, donde se dirimieron las violaciones a los Derechos Humanos derivadas de la desaparición forzada y el papel del Estado de Honduras como garante. Allí, la CIDH determinó que "Ninguna actividad del Estado puede fundarse sobre el desprecio a la dignidad humana" y que "El ejercicio de la función pública tiene unos limites que derivan de que los derechos humanos son atributos inherentes a la dignidad bumana y, en consecuencia, superiores al poder del Estado." .

7 Corte IDH, Velásquez Rodríguez Vs. Honduras, 1988, párr. 154

8 Ibid., párr. 165 
El fallo da cuenta de la fuerza argumental del concepto de dignidad humana, en tanto la $\mathrm{CIDH}$ se refiere a la actitud del Estado frente a las personas que cometieron un delito y deja claro que la naturaleza humana no cambia por ello, e incluso los peores delincuentes siguen siendo seres humanos con dignidad y como tales, gozan de todos los derechos y estándares de vida digna.

Puntualmente, referido a las condiciones de detención de las personas privadas de su libertad, existe una problemática en torno al discurso deshumanizante -y otra vez podemos referirnos a la construcción de realidad del lenguaje- reinante en la población "extramuros", que legitima la inacción del Estado o su desprecio por la dignidad humana. No existe -o por lo menos se halla invisibilizado- un repudio social referido a las infrahumanas condiciones de detención que sufren las personas procesadas o condenadas en algunas prisiones del mundo; y esto se debe a que el ser humano desde lo discursivo y luego en el plano real, se ve cosificado, hallando la justificación en la infracción a las pautas sociales por la comisión de un delito.

La función creativa descripta por la $\mathrm{CIDH}$ en este caso, permite ampliar el concepto de dignidad humana a la vez que le pone límites al Estado en virtud del mismo.

Otro de los casos analizados por los autores es el de Villagrán Morales vs. Guatemala, conocido como "el caso de los niños de la calle". En este fallo, se juzga la responsabilidad del Estado en el secuestro, tortura y homicidio de cinco jóvenes que vivían en la calle, dos de ellos menores de edad. En el marco del proceso, se acreditó que cuatro de las víctimas fueron introducidas en el baúl de un auto, frente a lo cual la Corte determinó que "aun cuando no bubiesen existido otros maltratos físicos o de otra índole, esa acción por sí sola debe considerarse claramente contraria al respeto debido a la dignidad inberente al ser bumano".

9 Corte IDH, “Niños de la Calle" - Villagrán Morales y otros Vs. Guatemala, 1999, párr. 164. 
Asimismo, del voto concurrente de Cançado Trindade y Abreu Burelli surge que "La privación arbitraria de la vida no se limita, pues, al ilicito del homicidio; se extiende igualmente a la privación del derecho de vivir con dignidad. Esta visión conceptualiza el derecho a la vida como perteneciente, al mismo tiempo, al dominio de los derechos civiles y políticos, así como al de los derechos económicos, sociales y culturales, ilustrando así la interrelación e indivisibilidad de todos los derechos bumanos" $"$.

La función creativa de la dignidad humana, se configura de manera perfecta en este caso. En tanto, los jueces indican que la dignidad no puede limitarse a evitar abusos del poder estatal, sino que la relaciona incluso con el disfrute y el goce de una vida digna.

La interpretación extensiva del voto concurrente de estos jueces da cuenta de la magnífica posibilidad que otorga este concepto para crear estándares cada vez más amplios en materia de protección de derechos.

\section{Conclusión}

En el presente trabajo dimos cuenta de la dificultad existente en la definición del concepto de dignidad humana, de las tensiones en torno a su contenido y de la peligrosidad real de asignarle una definición inmutable en tiempo y espacio. En la medido que ello atente contra la utilidad práctica que ha forjado en los últimos años como fundamento en el proceso de constitución de los derechos humanos.

Intentamos demostrar que, ante la imposibilidad de dar una definición acabada de un concepto, éste se define por su uso. Es por ello que Habermas decide reconocer las funciones de la dignidad humana (como puente entre la obligación moral

\footnotetext{
10 Ibid., Voto concurrente conjunto de los jueces A .A. Cançado Trindade y A. Abreu Burelli, párr. 4.
} 
y la obligación legal, como aglutinante de las históricas generaciones de derechos fundamentales, como sismógrafo de la realidad que también propicia la indivisibilidad de los derechos humanos, y finalmente como función creativa).

Si bien no encontramos doctrinario o juez que se aventure a dar una definición de la dignidad humana, reconocimos en el trabajo de Bohorquez Monsalve y Aguirre Román, una amplitud de aquella función creativa de la que hablara Habermas. En el entendimiento de que la conceptualización de la dignidad pierde importancia frente a la interpretación jurisprudencial que de ella puedan hacer los organismos internacionales en casos concretos.

Los jueces tienen la obligación de ser creativos aun cuando el concepto de dignidad se les presente difuso o incompleto. Y es a través de pautas hermenéuticas como el principio pro homine que llenan de contenido, en cada caso, aquello que nos parece vacío desde el punto de vista teórico. Esto nos permite pensar que quizás sea el desarrollo de la teoría de la argumentación jurídica el fundamento de los derechos humanos y no la dignidad humana como concepto. 